\title{
Randomized investigation of the bioavailability of fluoride in saliva after administration of sodium fluoride, amine fluoride and fluoride containing bioactive glass dentifrices
}

\author{
Ella A. Naumova ${ }^{1}$, Moritz Staiger ${ }^{1}$, Ouafaa Kouji ${ }^{1}$, Jakov Modric ${ }^{1}$, Thessa Pierchalla', Maya Rybka', \\ Robert G. Hill ${ }^{2}$ and Wolfgang H. Arnold ${ }^{1 *}$ (D)
}

\begin{abstract}
Objectives: Bioactive glasses which degrade in aqueous solutions may release bioactive ions such as fluoride $\left(F^{-}\right)$ and support fluoride bioavailability in saliva. We investigated how these effects would be apparent in an in vivo experimental trial after toothbrushing in comparison with sodium fluoride and amine fluoride.
\end{abstract}

Material and methods: In this single-center, randomized, parallel in vivo trial with a three strata block design, where healthy subjects were randomly assigned into three groups. Each group brushed their teeth either with fluoridated bioactive glass containing dentifrice, with a sodium fluoride $(\mathrm{NaF})$ containing dentifrice or with amine fluoride (AmF) containing toothpaste. Saliva was collected time intervals before, immediately after, 30, 60 and 120 min after toothbrushing. Fluoride concentration was determined in supernatant saliva and salivary sediment using a fluoride ion selective electrode. The data were evaluated statistically using non-parametric tests.

Results: The increase of bioactive fluoride in supernatant saliva was higher after application of $\mathrm{NaF}$ or AmF compared to fluoridated bioactive glass. In salivary sediment bioavailability of fluoride lasted longer after application of fluoridated bioactive glass.

Conclusions: Toothbrushing with the fluoride containing bioactive glass dentifrices had positive effects on the fluoride bioavailability within two hours. Fluoride containing bioactive glass represent a new area for investigation in caries prophylaxis. The bioactive potential impact on the tooth remineralization should be examined further.

Trial registration: DRKS00016038.

\section{Introduction}

Fluoride is a key factor in both dental restorative and oral healthcare products [1]. Numerous studies demonstrated the effectiveness of fluoride in caries prevention and it is now acknowledged that fluorides are the most effective agents in caries prevention [1-4]. Fluorides enhance enamel surface remineralization, reducing its susceptibility

\footnotetext{
* Correspondence: wolfgang.arnold@uni-wh.de

${ }^{1}$ Department of Biological and Material Sciences in Dentistry, Faculty of Health, Witten/Herdecke University, Alfred-Herrhausen-Strasse 44, 58455 Witten, Germany

Full list of author information is available at the end of the article
}

to demineralization [5-9], increase the resistance of the apatite structure to acid attack and have antibacterial properties [10]. Because dentifrices are widely used in oral hygiene and caries prevention fluoride compounds are added to the majority of them. Various fluoride compounds are used in the different dentifrices of which the most common in Europe are sodium fluoride $(\mathrm{NaF})$ and amine fluoride (AmF). The caries preventive effect of fluoride is dependent on the fluoride bioavailability [11].

However, the bioavailability of fluoride after tooth brushing is limited to a relatively short time interval. It has been shown, that the salivary fluoride level is back to

(c) The Author(s). 2019 Open Access This article is distributed under the terms of the Creative Commons Attribution 4.0 International License (http://creativecommons.org/licenses/by/4.0/), which permits unrestricted use, distribution, and reproduction in any medium, provided you give appropriate credit to the original author(s) and the source, provide a link to the Creative Commons license, and indicate if changes were made. The Creative Commons Public Domain Dedication waiver (http://creativecommons.org/publicdomain/zero/1.0/) applies to the data made available in this article, unless otherwise stated. 
baseline after tooth brushing with conventional fluoride containing dentifrices after $120 \mathrm{~min}$ [12-15]. On the other hand, high fluoride doses are toxic and may result in enamel disruption such as fluorosis [16-18]. It has also been shown, that low doses of fluoride also enhance enamel remineralization [9]. In the light of increasing awareness in the population of the uptake of substances which may have an impact on general and oral health it is reasonable to reduce their uptake. Therefore, attempts to increase the bioavailability of fluoride in the oral cavity for a longer time period and to reduce the fluoride dose at the same time have been undertaken. Materials releasing calcium and fluoride ions for dentin and enamel remineralization have been the topics of intensive research [19]. A novel development is fluoridecontaining bioactive glass (F-bioactive glass) with a relative low fluoride content compared to the conventional fluoride containing dentifrices [20-22]. Fbioactive glasses are amorphous silicate glasses, which degrade in aqueous solutions $[10,23] . \mathrm{F}^{-}$.bioactive glass acts in aqueous solutions as a single source of both calcium, phosphate and fluoride ions [19]. During selective dissolution they may release bioactive ions such as fluoride, strontium, or calcium [20, 24]. After hydrolysis, selective dissolution and the ion exchange of $\mathrm{F}^{-}$bioactive glass in an aqueous environment apatite can precipitate on biological surfaces and elicit an interfacial biological response, such as bioactive fixation, resulting in inhibiting further dissolution, and decrease complete resorption of the material [10]. Bioactive glasses are biocompatible and effective for bone regeneration, bone engineering $[25,26]$ and for the application in the oral cavity [27].

In medicine bioactive glasses have been developed for the treatment of osteoporosis by substitution of calcium with strontium [28] and for the application in orthopedic surgery [25]. Strontium substituted bioactive glass increases osteoblast proliferation and alkaline phosphatase activity [28]. Fluoride-containing bioactive glasses also impact osteoblast behavior and activity, enhance and control of their proliferation, differentiation and mineralization [10]. Bioactive glasses release bioactive ions slowly which results in a prolonged biological effect [25]. Because of the ability to release fluoride locally the fluoride-containing bioactive glasses have already been used in dentistry for various clinical applications e. g. for the treatment of dentin hypersensitivity $[10,29]\}$ and for regeneration of osseous defects of the alveolar ridge [10, $22,25,30]$. It has also been shown in in-vitro experiments, that F-Bioactive glass induces fluor-hydroxyapatite formation on enamel surfaces [21, 22, 31, 32]. Another preliminary study demonstrated, that fluoride-containing bioactive glass enhances enamel remineralization [21]. Bioactive glasses can bond to hard and soft tissues [10].
However, to our knowledge there are no comparative clinical studies about the bioavailability of fluoride in oral cavity after toothbrushing with a F-bioactive glass containing dentifrice. It was therefore the aim of this in-vivo study to investigate the dynamics of fluoride bioavailability in salivary compartments (supernatant and sediment) up to two hours after standardized toothbrushing with F-bioactive glass dentifrice and compare it with the fluoride bioavailability in salivary compartments after application of dentifrices containing $\mathrm{NaF}$ and $\mathrm{AmF}$. The null hypothesis of this study assumed that there are no differences in the fluoride bioavailability between the different dentifrices in supernatant saliva and salivary sediment.

\section{Material and methods}

Prior to the investigation the study has been approved by the ethical committee (Nr. 170/2016) of Witten/Herdecke University. This study has been registered in the German Clinical Trials Register (\# DRKS00016038). Registration was done after the study has been conducted and the results suggested a publication and further continuation of this research. The authors confirm that all ongoing and related trials for this drug/intervention are registered. All experiments were performed in accordance with relevant guidelines, and informed written consent was obtained from all participants.

\section{Test subjects}

Sixty subjects were asked to participate in this study. Twelve refused to participate. Forty eight test subjects aged between 20 and 28 years finally participated in this parallel study (Fig. 1). All participants received written instructions and a schedule. Participants were further asked to avoid fluoride-rich food products such as tea, fish and specified mineral water during the period but had no restriction concerning drinking water. All test subjects were residents in the area with $\approx 0.2 \mathrm{ppm}$ fluoride in the drinking water and normally used fluoride containing dentifrices twice daily. They were randomly and evenly distributed into three groups of eight male and eight female subjects. All subjects received verbal and written information about the investigation, as well as written instructions regarding the schedule of the study and proper tooth brushing methods. The inclusion criteria were satisfactory oral and general health. The exclusion criterion was the presence of active caries or periodontal disease and systemic disease.

\section{Materials}

Three commercially available dentifrices with three different fluoride formulations, F-bioactive glass (530 ppm) containing dentifrice (BioMin $\mathrm{F}^{\circ}$; BIOMIN, London, UK), a $\mathrm{NaF}(1450 \mathrm{ppm})$ containing dentifrice (Eurodont, MAXIM Markenprodukte, Pulheim, Germany) and an AmF (1450 


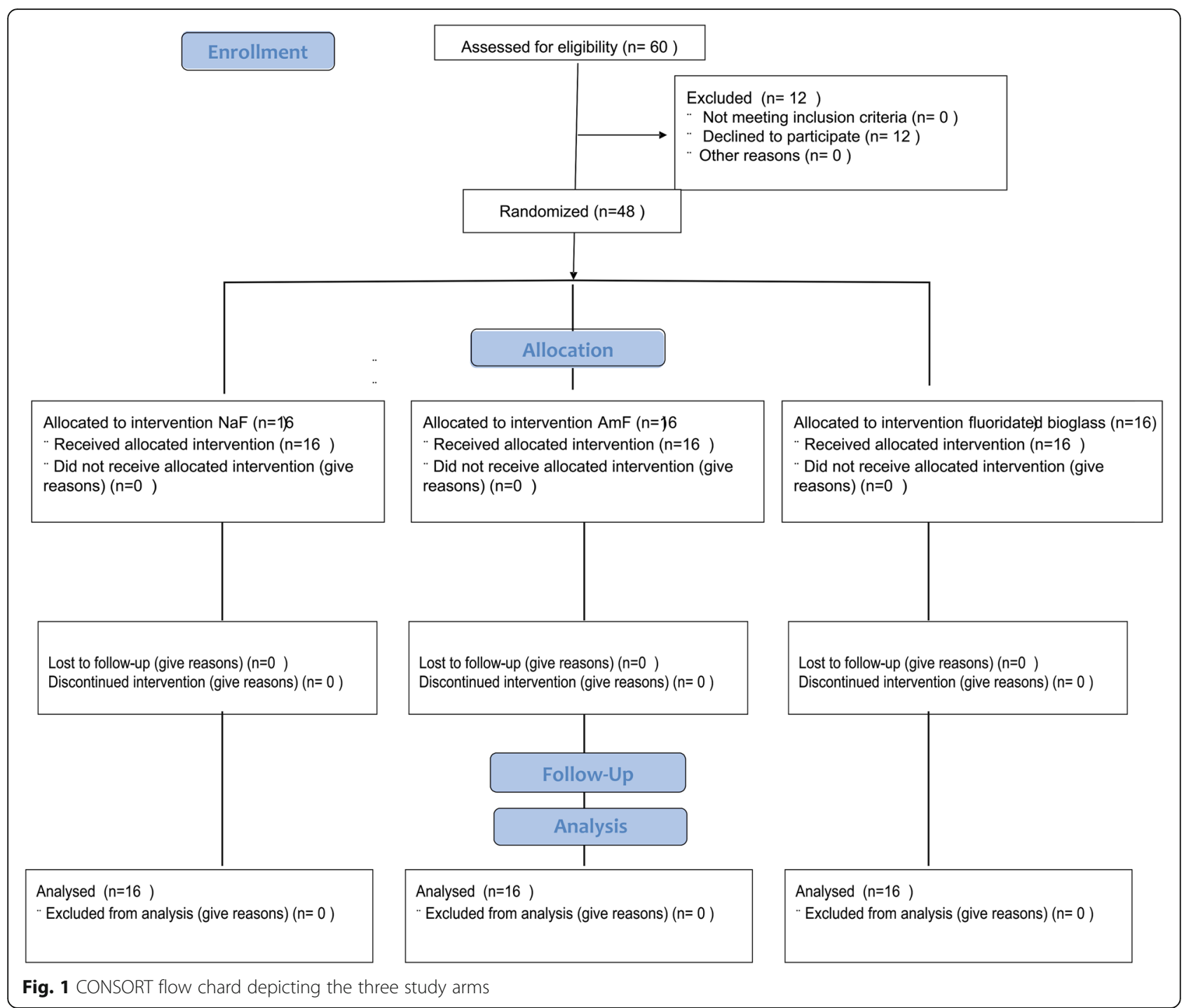

ppm) containing toothpaste (Elmex, CP Gaba, Hamburg, Germany) were used for toothbrushing in the present study. The ingredients of the dentifrices are listed in Table 1.

\section{Study design and sample collection}

The study was carried out as a parallel study and done at 2 .p.m. for each experiment. Prior to the experiments salivary flow rate was determined and only normal secretors $(0.25-1.0 \mathrm{~g} / \mathrm{min})$ were included. For standardization of tooth brushing all test subjects brushed their teeth with the same technique (Bass' method of tooth brushing) [33]. Saliva was collected before (T0), immediately after (T1), 30 (T2), and 120 (T3) minutes after tooth brushing by spitting into a plastic tube. Mouth rinsing was conducted immediately after collection of sample $\mathrm{T} 1$ with $10 \mathrm{ml}$ tap water within $10 \mathrm{~s}$. After a washout period of two weeks the groups repeated the brushing cycle. All experiments were repeated three times. After collection saliva was centrifuged (B Centrifuge, Beckman Coulter GmbH, Krefeld, Germany) at a speed of $3024 \mathrm{x} \mathrm{g}$ for $10 \mathrm{~min}$. in microcentrifuge tubes to separate the cell-free supernatant saliva and the cell containing sediment. Supernatant saliva and salivary sediment were separated and frozen at $-80^{\circ}$ until fluoride determination.

\section{Fluoride measurement}

One $\mathrm{ml}$ supernatant saliva was taken and mixed with 1 $\mathrm{ml}$ of a TISAB II buffer solution (Thermo Electron, Beverly, MA, USA). For equal fluoride ion distribution during the measurement a magnetic stick stirrer (size 2 $\mathrm{mm} \times 5 \mathrm{~mm}$ ) was used. The sediment was removed from the centrifuge tube, dispersed in $250 \mathrm{ml}$ TISAB II buffer solution (Vortex-Genie 2 Scientific Industries, New York, USA) in a new tube and weighted again. The fluoride concentration was determined using a fluoride 
Table 1 Ingedients of the detifrices

\begin{tabular}{|c|c|c|}
\hline Name & Active fluoride component & Other ingredients \\
\hline \multirow[t]{9}{*}{ BioMin F } & \multirow[t]{9}{*}{ Bioactive glass } & Glycerin; \\
\hline & & Silica; \\
\hline & & PEG 400; \\
\hline & & Fluoro Calcium Phpspho Slicate; \\
\hline & & Sodium Lauryl Sulphate; \\
\hline & & Titanium Dioxide; \\
\hline & & Aroma; \\
\hline & & Carbomer; \\
\hline & & Potassium Acesulfame \\
\hline \multirow[t]{11}{*}{ eurodont } & \multirow[t]{11}{*}{$\mathrm{NaF}$} & Aqua; \\
\hline & & Hydrated silica; \\
\hline & & Sorbitol; \\
\hline & & Propylene Glycol; \\
\hline & & $\mathrm{NaF}$ \\
\hline & & Potassium Nitrate; \\
\hline & & Sodium Cq4-16 Olefin; \\
\hline & & Sulfonate; \\
\hline & & Aroma; \\
\hline & & Cellulose gum; \\
\hline & & Sodium Saccarin \\
\hline \multirow[t]{11}{*}{ Elmex } & \multirow[t]{11}{*}{$\mathrm{AmF}$} & Aqua; \\
\hline & & Hydrated silica; \\
\hline & & Sorbitol; \\
\hline & & Hydroxyaethylcellulose; \\
\hline & & Olafluor; \\
\hline & & Aroma; \\
\hline & & Limonene; \\
\hline & & $\mathrm{Cl} 77,891$ \\
\hline & & Sodium; \\
\hline & & Saccarin; \\
\hline & & Hydrochloric acid \\
\hline
\end{tabular}

ion selective electrode (96-09 Orion, Thermo Electron, Beverly, MA, USA). The protocol of fluoride determination followed exactly as described by [15].

\section{Statistics}

A power calculation, based on the data of a previous study [34], was performed with a power of 0.8 and $\alpha=$ 0.05 (mean $1=0.04$; STD $1=0.084$; mean $2=0.72$; STD $2=0.88$ ). The power analysis revealed a minimum sample size of 14 subjects. As program for the power analysis Axum 7 (Mathsoft, Cambridge, Massachusetts, USA) was used.

From the repeated measurements of every subject the mean value was calculated for each measurement and used for statistical evaluation. The Shapiro-Wilk and Kolmogorov-Smirnov test have been used for testing the normality of the data. As these tests were negative the results were evaluated statistically with the nonparametric Mann-Whitney $U$ test for independent variables and the Wilcoxon sign test for related variables. Descriptive statistical data were presented as boxplot graphics and tables. As statistic program served Graphpad Prism Ver. 7.0 (Graphpad, La Jolla, Ca, USA).

\section{Results}

\section{Supernatant saliva}

Comparison of the fluoride content in supernatant saliva at the different collection times revealed statistically significant differences between $\mathrm{T} 0$ and $\mathrm{T} 1$ for all fluoride compounds. Fluoride content was still significantly higher compared to T0 at T2 and T3 (Table 2 and Fig. 2). After $\mathrm{NaF}$ application the fluoride content in the supernatant saliva reached the baseline level after $120 \mathrm{~min}$ and in $\mathrm{AmF}$ after $30 \mathrm{~min}$ (Table 2 and Fig. 2).

Between the different fluoride compounds statistically significantly differences were found between $\mathrm{F}^{-}$bioactive glass and $\mathrm{NaF}$ respectively AmF at $\mathrm{T} 1$, between $\mathrm{F}$ bioactive glass and $\mathrm{NaF}$ at $\mathrm{T} 2$, between $\mathrm{F}^{-}$bioavtive glass and $\mathrm{NaF}$ respectively AmF at T3. All results are summarized in Table 3. All descriptive data of the distribution of the measured values of supernatant saliva are summarized in Table 4.

\section{Salivary sediment}

Comparison of the fluoride content in salivary sediment at the different collection times revealed statistically significant differences between $\mathrm{T} 0$ and $\mathrm{T} 1$ for all fluoride compounds. Fluoride content was still significantly higher compared to $\mathrm{T} 0$ at $\mathrm{T} 2$ in $\mathrm{NaF}$ and AmF. but not for F-bioactive glass. Between T0 and T3 a significant difference was found only for AmF (Table 5 and Fig. 3).

In salivary sediment the fluoride content was significantly lower after AmF application than after F-bioactive glass or $\mathrm{NaF}$ application (Table 6). At one collection point $\mathrm{T} 2$ a significant difference between all fluorides compounds was observed. The NaF content was higher than with the other compounds (Table 6.). At collection point T3 no difference in the fluoride content was observed between F-bioactive glass and AmF (Table 5. and Fig. 3). All descriptive data of the distribution of the

Table 2 Fluoride content at different time points in supernatant saliva

\begin{tabular}{llll}
\hline & $\mathrm{T} 0-\mathrm{T} 1$ & $\mathrm{~T} 0-\mathrm{T} 2$ & $\mathrm{~T} 0-\mathrm{T} 3$ \\
\hline F-bioactive glass & $p<0.001$ & $p<0.001$ & $p<0.001$ \\
NaF & $p<0.001$ & $p<0.001$ & $p=0.129$ \\
AmF & $p<0.001$ & $p=0.687$ & $p=1.000$ \\
\hline
\end{tabular}




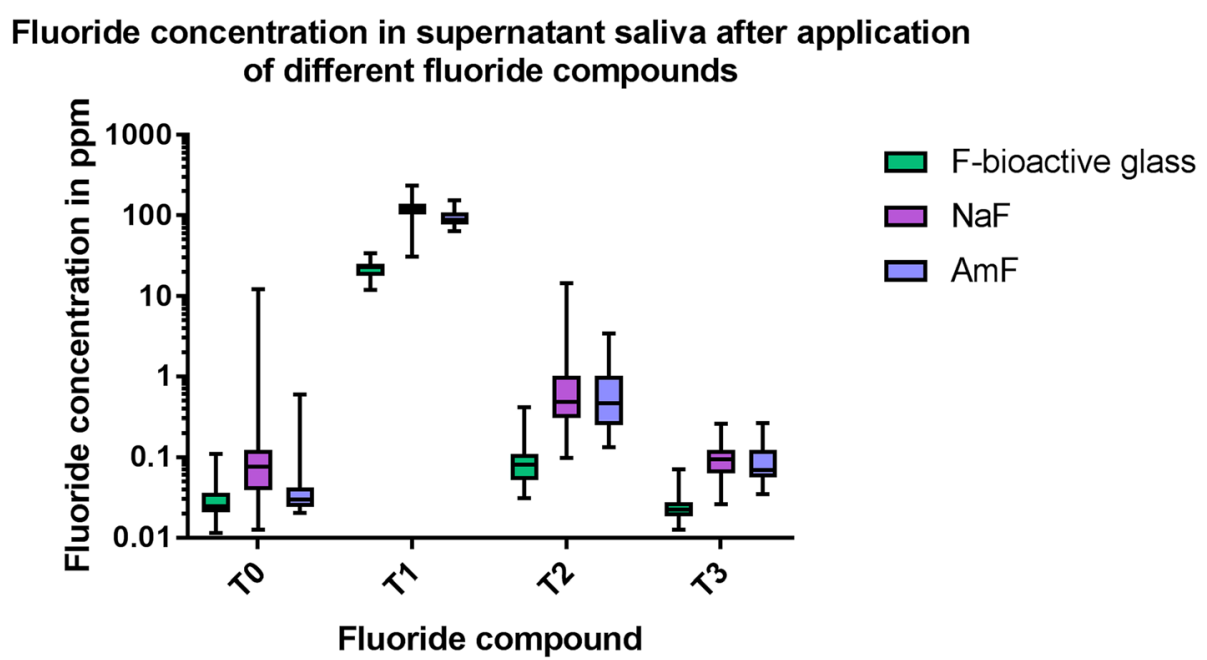

Fig. 2 Boxplot graphics of the data distribution of the fluoride content in supernatant saliva after application of different fluoride compounds at different collection times (y axis log scale)

measured values of salivary sediment are summarized in Table 7.

\section{Discussion}

The most important unmet need in caries disease prophylaxes is the achievement of apatite demineralizationremineralization balance. The protection of apatite from destruction can be achieved by the application of the protective substances that can slow or prevent tooth demineralization. Force the remineralization or decrease

Table 3 Differences between fluoride content in different fluoride compounds at different collection times in supernatant saliva

\begin{tabular}{|c|c|c|}
\hline \multicolumn{3}{|l|}{ T0 } \\
\hline & F-bioactive glass & $A m F$ \\
\hline $\mathrm{NaF}$ & $p<0.001$ & $p<0.001$ \\
\hline AmF & $p=0.217$ & \\
\hline \multicolumn{3}{|l|}{ T1 } \\
\hline & F-bioactive glass & AmF \\
\hline $\mathrm{NaF}$ & $p<0.001$ & $p=0.024$ \\
\hline AmF & $p<0.001$ & \\
\hline \multicolumn{3}{|l|}{ T2 } \\
\hline & F-bioactive glass & $A m F$ \\
\hline $\mathrm{NaF}$ & $p<0.001$ & $p<0.001$ \\
\hline $\mathrm{AmF}$ & $p=0.246$ & \\
\hline \multicolumn{3}{|l|}{ T3 } \\
\hline & F-bioactive glass & $A m F$ \\
\hline $\mathrm{NaF}$ & $p<0.001$ & $p<0.001$ \\
\hline AmF & $p=0.036$ & \\
\hline
\end{tabular}

the development of the oral biofilm with the pathogenic microorganisms. Which produce acid for the HAP destruction. Fluoride has all three of these characteristics: stabilizing the demineralization-remineralization balance $[35,36]$. decreasing the development of the plaque [37] and has antibacterial activity against streptococci mutans [38]. which are accumulated in the oral biofilm [12].

Fluoride occurs in the oral cavity in two forms: active (free fluoride ions) and inactive (bound or complexed fluoride). depending on the $\mathrm{pH}$. ionic strength and protein

Table 4 Descriptive data of the measured values of fluoride content in supernatant saliva in ppm

\begin{tabular}{llll}
\hline & Median & Minimum & Maximum \\
\hline T0 & & & \\
F-bioactive glass & 0.024 & 0.01 & 0.11 \\
NaF & 0.07 & 0.01 & 12.27 \\
AmF & 0.04 & 0.01 & 2.51 \\
T1 & & & \\
F-bioactive glass & 23.05 & 12.00 & 33.73 \\
NaF & 122.83 & 30.70 & 234.67 \\
AmF & 109.00 & 66.33 & 168.33 \\
T2 & & & \\
F-bioactive glass & 0.08 & 0.03 & 0.41 \\
NaF & 0.48 & 0.10 & 14.50 \\
AmF & 0.34 & 0.09 & 6.32 \\
T3 & & & \\
F-bioactive glass & 0.02 & 0.01 & 0.07 \\
NaF & 0.09 & 0.03 & 0.26 \\
AmF & 0.07 & 0.02 & 0.76 \\
\hline
\end{tabular}


Table 5 Fluoride content at different time points in salivary sediment

\begin{tabular}{llll}
\hline & T0 - T1 & T0 - T2 & T0 - T3 \\
\hline F-bioactive glass & $p<0.001$ & $p=0.303$ & $p=0.246$ \\
NaF & $p<0.001$ & $p<0.001$ & $p=0.012$ \\
AmF & $p<0.001$ & $p<0.001$ & $p<0.001$ \\
\hline
\end{tabular}

concentration; these two forms are often easily interchangeable by simply changing the $\mathrm{pH}$ [39]. The active form of fluoride determines its bioavailability.

After application of fluoride containing dentifrices the fluoride bioavailability in saliva increases dramatically for a short time interval and then declines reaching the baseline level after about $120 \mathrm{~min}$ [13, 15, 34, 40-42]. Several studies demonstrated that the content of fluoride in supernatant saliva is much lower than in the salivary sediment [14, 15]. NaF dissolves in saliva quickly and has a rapid clearance because it is swallowed with saliva. The amino group of AmF is supposed to adhere to organic surfaces and remain longer in the oral cavity. Not much is known about the bioactive potential of the Fbioactive glass in the oral cavity [10]. So far there is no in-vivo study about the distribution and retention of fluoride in supernatant saliva and salivary sediment for F-bioactive glass containing dentifrice.

The primary outcome in the present study was the adjusted fluoride bioavailability dynamic in supernatant saliva and salivary sediment during two hours after standardised toothbrushing. With the fluoride-containing bioactive glasses dentifrice compared to the dentifrice with the other fluoride formulations followed by a oneweek washout period.
Table 6 Differences between fluoride content in different fluoride compounds at different collection times in sliavary sediment

\begin{tabular}{|c|c|c|}
\hline \multicolumn{3}{|l|}{ TO } \\
\hline & F-bioactive glass & AmF \\
\hline $\mathrm{NaF}$ & $p=0.247$ & $p<0.001$ \\
\hline AmF & $p<0.001$ & \\
\hline \multicolumn{3}{|l|}{ T1 } \\
\hline & F-bioactive glass & AmF \\
\hline $\mathrm{NaF}$ & $p=0.265$ & $p<0.001$ \\
\hline AmF & $p<0.001$ & \\
\hline \multicolumn{3}{|l|}{$\mathrm{T} 2$} \\
\hline & F-bioactive glass & AmF \\
\hline $\mathrm{NaF}$ & $p<0.001$ & $p<0.001$ \\
\hline AmF & $p<0.001$ & \\
\hline \multicolumn{3}{|l|}{ T3 } \\
\hline & F-bioactive glass & AmF \\
\hline $\mathrm{NaF}$ & $p<0.001$ & $p<0.001$ \\
\hline AmF & $p=0.002$ & \\
\hline
\end{tabular}

The results of the present study showed. That there is a difference between the fluoride bioavailability in supernatant saliva and salivary sediment for all three dentifrices with the different fluoride compounds. Therefore the null hypothesis has been rejected. In supernatant saliva the fluoride bioavailability after brushing with the NaF containing dentifrice was back to baseline after 120 min whereas after AmF containing toothpaste application it was back to base line as soon as $30 \mathrm{~min}$ after application. Fluoride bioavailability in the supernatant saliva after F-bioactive glass dentifrice application remained significantly higher than the

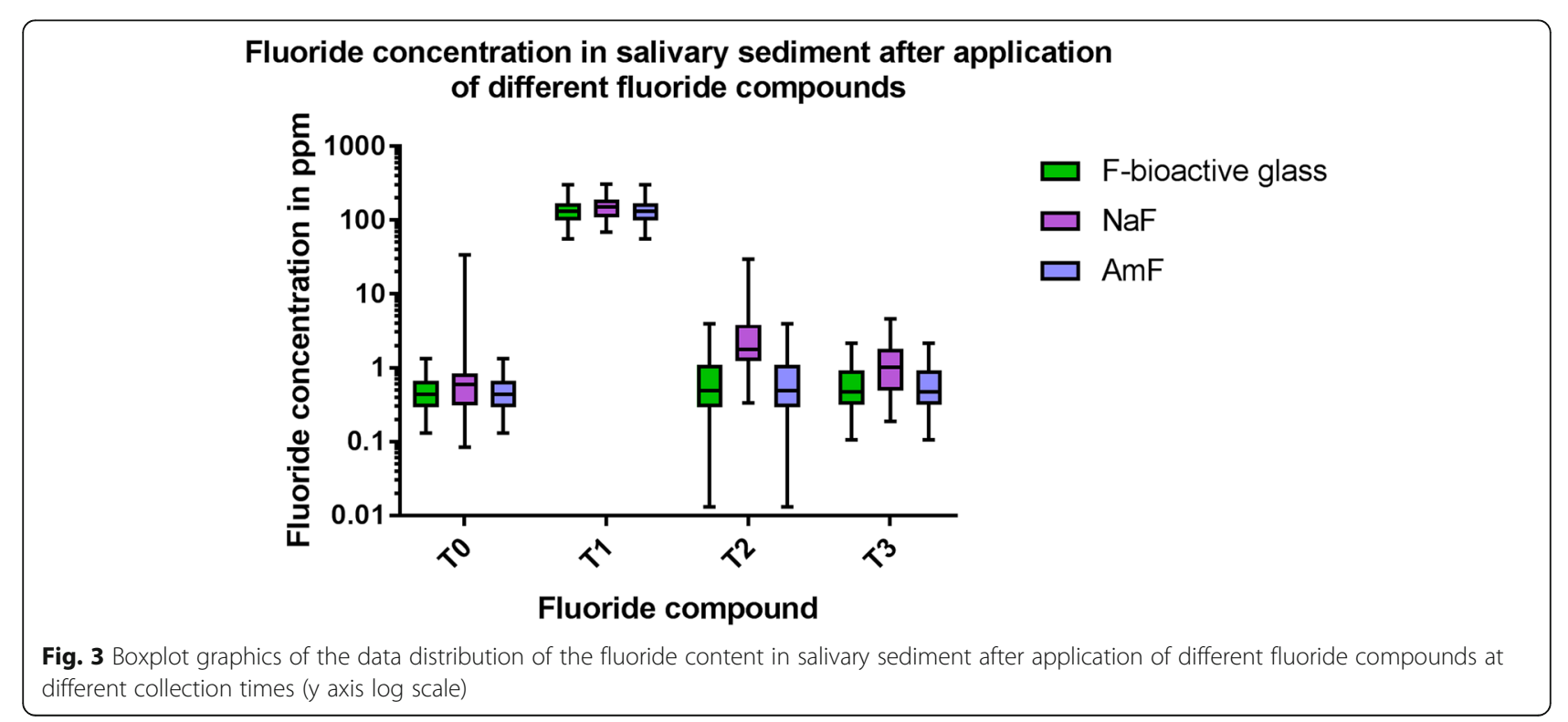


Table 7 Descriptive data of the measured values of fluoride content in salivary sediment in ppm

\begin{tabular}{llll}
\hline & Median & Minimum & Maximum \\
\hline T0 & & & \\
F-bioactive glass & 0.44 & 0.13 & 1.34 \\
NaF & 0.59 & 0.08 & 33.93 \\
AmF & 0.03 & 0.02 & 1.90 \\
T1 & & & \\
F-bioactive glass & 131.84 & 33.82 & 300.91 \\
NaF & 149.76 & 68.16 & 307.59 \\
AmF & 19.07 & 2.26 & 74.83 \\
T2 & & & \\
F-bioactive glass & 0.81 & 0.01 & 3.91 \\
NaF & 1.77 & 0.34 & 29.77 \\
AmF & 0.72 & 0.3 & 3.91 \\
T3 & & & \\
F-bioactive glass & 0.47 & 0.11 & 2.18 \\
NaF & 1.02 & 0.19 & 4.61 \\
AmF & 0.22 & 0.04 & 2.04 \\
\hline
\end{tabular}

baseline until $120 \mathrm{~min}$ after application. Therefore. the original assumption. That F-bioactive glass may release fluoride for a prolonged time interval than two hours after toothbrushing might be accepted. For salivary sediment completely. Different results were obtained. Like supernatant saliva in salivary sediment the fluoride bioavailability was back to the baseline level after $120 \mathrm{~min}$ after application of a $\mathrm{NaF}$ containing dentifrice. However. after application of an AmF containing dentifrice the fluoride bioavailability remained significantly higher compared to the baseline until $120 \mathrm{~min}$ after application. After application of a F-bioactive glass dentifrice the fluoride bioavailability was back to baseline as soon as $30 \mathrm{~min}$ after application. It may be speculated that the fact that the fluoride is bound the bioactive glass and not to the proteins of the sediment is the reason for the quick clearance from salivary sediment. With respect to $\mathrm{NaF}$ and $\mathrm{AmF}$ the results confirm previous studies about the clearance of fluoride in whole saliva [43-46]. Only few studies exist about the fluoride bioavailability after application of $\mathrm{NaF}$ or AmF in salivary sediment $[14,15]$. It has been discussed whether salivary sediment acts as fluoride reservoir releasing fluoride slowly for a prolonged time. Fluoride bioavailability varies also in the different oral niches where different surfaces influence the fluoride bioavailability [12, $47,48]$. Other studies investigated the fluoride bioavailability in dental plaque and reported elevated fluoride concentrations after toothbrushing $[44,46]$.

However, in contrast to both other applied fluoride compounds the fluoride bioavailability in salivary sediment could not be proven after application of F-bioactive glass. Therefore, it might be assumed. That the mechanisms for liberating bioavailable fluoride for $\mathrm{NaF}$. AmF and fluoride-containing bioactive glass from salivary sediment might be completely different. Whether this has an influence on the remineralization of the enamel surface has to be elucidated in further experimental and clinical studies.

\section{Conclusions}

Within the limits of this investigation it may be concluded that administration of F-bioactive glass with 530 ppm $\mathrm{F}^{-}$results in a similar fluoride bioavailability in supernatant saliva as administration of $\mathrm{NaF}$ or $\mathrm{AmF}$ with $1450 \mathrm{ppm} \mathrm{F}^{-}$.

\section{Abbreviations \\ AmF: Amine fluoride; $F^{-}$: Fluoride; NaF: Sodium fluoride; TO: Baseline; T1: Immeditedly after fluoride application; T2: 30 Minutes after fluoride application; T3: 120 Minutes after fluoride application}

\section{Acknowledgements \\ We would like to thank Biomin Technologies Inc. for providing the BioMinF toothpastes.}

\section{Authors' contributions}

EAN: Wrote the manuscript, supervised the fluoride measurements, MS: AmF fluoride measurements sediment, OK: NaF fluoride measurements, JM: Bioglass fluoride measurements sediment, TP: AmF fluoride measurements supernatant, MR: Bioglass fluoride measurements supernatant, RH: Planning the project, manuscript correction, WHA: Calculation of statistics, supervision of the project, final manuscript correction. All authors read and approved the final manuscript.

\section{Funding}

This study was funded by the institutional budget of Witten/Herdecke University.

\section{Availability of data and materials}

The datasets used and/or analysed during the current study are available from the corresponding author on reasonable request.

\section{Ethics approval and consent to participate}

Prior to the investigation the study has been approved by the ethical committee (Nr. 170/2016) of Witten/Herdecke University. This study has been registered in the German Clinical Trials Register (\# DRKS00016038).

Registration was done after the study has been conducted and the results suggested a publication and further continuation of this research. The authors confirm that all ongoing and related trials for this drug/intervention are registered. All experiments were performed in accordance with relevant guidelines, and informed written consent was obtained from all participants.

Consent for publication

Not applicable.

\section{Competing interests}

The authors declare that they have no competing interests.

\section{Author details}

'Department of Biological and Material Sciences in Dentistry, Faculty of Health, Witten/Herdecke University, Alfred-Herrhausen-Strasse 44, 58455 Witten, Germany. ${ }^{2}$ Institute of Dentistry, Barts and The London School of Medicine and Dentistry, Queen Mary University of London, London E1 4NS, UK. 


\section{Received: 8 February 2019 Accepted: 31 May 2019}

Published online: 18 June 2019

\section{References}

1. Selwitz RH, Ismail Al, Pitts NB. Dental caries. Lancet. 2007;369(9555):51-9. https://doi.org/10.1016/S0140-6736(07)60031-2 Epub 2007/01/09. PubMed PMID: 17208642

2. Featherstone JD. The science and practice of caries prevention. J Am Dent Assoc. 2000;131(7):887-99 Epub 2000/08/01. PubMed PMID: 10916327.

3. Griffin SO, Regnier E, Griffin PM, Huntley V. Effectiveness of fluoride in preventing caries in adults. J Dent Res. 2007;86(5):410-5 Epub 2007/04/25. PubMed PMID: 17452559

4. FDI. FDI policy statement on promoting oral health through water fluoridation: revised version adopted by the FDI General Assembly: 13 September 2014, New Delhi, India. Int Dent J. 2014;64(6):293-4 Epub 2014/ 11/25. doi: 10.1111/idj.12150. PubMed PMID: 25417783.

5. Arnold WH, Dorow A, Langenhorst S, Gintner Z, Banoczy J, Gaengler P. Effect of fluoride toothpastes on enamel demineralization. BMC Oral Health. 2006;6:8. https://doi.org/10.1186/1472-6831-6-8 Epub 2006/06/17. PubMed PMID: 16776820; PubMed Central PMCID: PMC1543617.

6. Ten Cate JM. Fluorides in caries prevention and control: empiricism or science. Caries Res. 2004;38(3):254-7. https://doi.org/10.1159/000077763 PubMed PMID: 15153697. Epub 2004/05/22.

7. ten Cate JM, Buijs MJ, Miller CC, Exterkate RA. Elevated fluoride products enhance remineralization of advanced enamel lesions. J Dent Res. 2008; 87(10):943-7 Epub 2008/09/24. PubMed PMID: 18809748.

8. ten Cate JM, Duijsters PP. Alternating demineralization and remineralization of artificial enamel lesions. Caries Res. 1982;16(3):201-10 Epub 1982/01/01. PubMed PMID: 6953998.

9. Naumova EA, Niemann N, Aretz L, Arnold WH. Effects of different amine fluoride concentrations on enamel remineralization. J Dent. 2012:40(9):7505. https://doi.org/10.1016/j.jdent.2012.05.006 PubMed PMID: 22677913.

10. Shah FA. Fluoride-containing bioactive glasses: glass design, structure, bioactivity, cellular interactions, and recent developments. Mater Sci Eng C Mater Biol Appl. 2016;58:1279-89. https://doi.org/10.1016/j.msec.2015.08.064 Epub 2015/10/20. PubMed PMID: 26478431.

11. ten Cate JM, van Loveren C. Fluoride mechanisms. Dent Clin North Am. 1999;43(4):713-42 vii. Epub 1999/11/30. PubMed PMID: 10553252.

12. Naumova EA, Dickten $C$, Jung $R$, Krauss $F$, Ruebesamen $H$, Schmütsch $K$, et al. Dynamics of the Fluoride Bioavailability in the Biofilm of Different Oral Surfaces after Amine Fluoride and Sodium Fluoride Application. Sci Rep. 2016:6:18729. https://doi.org/10.1038/srep18729.

13. Naumova EA, Gaengler $P$, Zimmer S, Arnold WH. Influence of individual saliva secretion on fluoride bioavailability. Open Dent J. 2010;4:185-90. https://doi.org/10.2174/1874210601004010185 Epub 2011/01/12. PubMed PMID: 21221176; PubMed Central PMCID: PMC3018097.

14. Naumova EA, Kuehnl P, Hertenstein P, Markovic L, Jordan RA, Gaengler $P$, et al. Fluoride bioavailability in saliva and plaque. BMC Oral Health. 2012;12:3.

15. Naumova EA, Sandulescu T, Bochnig C, Gaengler P, Zimmer S, Arnold WH. Kinetics of fluoride bioavailability in supernatant saliva and salivary sediment. Arch Oral Biol. 2012:57(7):870-6. https://doi.org/10.1016/j. archoralbio.2012.01.011 Epub 2012/02/22. PubMed PMID: 22341566.

16. Bhagavatula $P$, Levy SM, Broffitt B, Weber-Gasparoni K, Warren JJ. Timing of fluoride intake and dental fluorosis on late-erupting permanent teeth. Commun Dent Oral Epidemiol. 2015. https://doi.org/10.1111/cdoe.12187 Epub 2015/07/23. PubMed PMID: 26198477.

17. Perez-Perez N, Torres-Mendoza N, Borges-Yanez A, Irigoyen-Camacho ME. Dental fluorosis: concentration of fluoride in drinking water and consumption of bottled beverages in school children. J Clin Pediatric Dent. 2014;38(4):338-44 Epub 2015/01/13. PubMed PMID: 25571686.

18. Perrott KW. Severe dental fluorosis and cognitive deficits. Neurotoxicol Teratol. 2015. https://doi.org/10.1016/j.ntt.2015.01.001 Epub 2015/01/13. PubMed PMID: 25576911.

19. Davis HB, Gwinner F, Mitchell JC, Ferracane JL. Ion release from, and fluoride recharge of a composite with a fluoride-containing bioactive glass. Dent Mater. 2014;30(10):1187-94. https://doi.org/10.1016/j.dental.2014.07.012 Epub 2014/09/02. PubMed PMID: 25175342; PubMed Central PMCID: PMCPMC4228797

20. Brauer DS, Karpukhina N, O'Donnell MD, Law RV, Hill RG. Fluoride-containing bioactive glasses: effect of glass design and structure on degradation, $\mathrm{pH}$ and apatite formation in simulated body fluid. Acta Biomater. 2010;6(8): 3275-82. https://doi.org/10.1016/j.actbio.2010.01.043 Epub 2010/02/06. PubMed PMID: 20132911.

21. Hill RG, Anderson P, Mneimne M. A New Remineralizing Calcium Phosphosilicate Additive for Toothpastes. In: International Association for Dental Research, editor. 94th General Session \& Exhibition of the IADR. Seoul: J Dent Res; 2016

22. Lynch E, Brauer DS, Karpukhina N, Gillam DG, Hill RG. Multi-component bioactive glasses of varying fluoride content for treating dentin hypersensitivity. Dent Mater. 2012;28(2):168-78. https://doi.org/10.1016/j. dental.2011.11.021 Epub 2011/12/27. PubMed PMID: 22197355.

23. Sriranganathan D, Chen $X$, Hing K, Kanwal N, Hill R. The effect of the incorporation of fluoride into strontium containing bioactive glasses. J Mater Sci: Mater Med. 2016;27(39):25-30. https://doi.org/10.1007/s10856015-5653-6.

24. Fredholm YC, Karpukhina N, Brauer DS, Jones JR, Law RV, Hill RG. Influence of strontium for calcium substitution in bioactive glasses on degradation, ion release and apatite formation. J R Soc Interface. 2012;9(70):880-9. https://doi.org/10.1098/rsif.2011.0387 Epub 2011/10/14. PubMed PMID: 21993007; PubMed Central PMCID: PMCPmc3306632.

25. Josset $Y$, Nasrallah $F$, Jallot $E$, Lorenzato M, Dufour-Mallet $O$, Balossier $G$, et al. Influence of physicochemical reactions of bioactive glass on the behavior and activity of human osteoblasts in vitro. J Biomed Mater Res A. 2003;67(4): 1205-18. https://doi.org/10.1002/jbm.a.20035 Epub 2003/11/19. PubMed PMID: 14624507

26. Han YJ, Loo SC, Lee J, Ma J. Investigation of the bioactivity and biocompatibility of different glass interfaces with hydroxyapatite, fluorohydroxyapatite and 585 bioactive glass. BioFactors. 2007;30(4):205-16 Epub 2008/07/09. PubMed PMID: 18607070.

27. Rodriguez O, Alhalawani A, Arshad S, Towler MR. Rapidly-Dissolving SilverContaining Bioactive Glasses for Cariostatic Applications. J Funct Biomater 2018;9(2). https://doi.org/10.3390/jfb9020028 Epub 2018/04/12. PubMed PMID: 29641491

28. Gentleman E, Fredholm YC, Jell G, Lotfibakhshaiesh N, O'Donnell MD, Hill RG et al. The effects of strontium-substituted bioactive glasses on osteoblasts and osteoclasts in vitro. Biomaterials. 2010;31(14):3949-56. https://doi.org/10.1016/j. biomaterials.2010.01.121 Epub 2010/02/23. PubMed PMID: 20170952.

29. Tai BJ, Bian Z, Jiang H, Greenspan DC, Zhong J, Clark AE, et al. Anti-gingivitis effect of a dentifrice containing bioactive glass (NovaMin) particulate. J Clin Periodontol. 2006;33(2):86-91. https://doi.org/10.1111/j.1600-051X.2005. 00876.x Epub 2006/01/31. PubMed PMID: 16441730

30. Lovelace TB, Mellonig JT, Meffert RM, Jones AA, Nummikoski PV, Cochran $\mathrm{DL}$. Clinical evaluation of bioactive glass in the treatment of periodontal osseous defects in humans. J Periodontol. 1998;69(9):1027-35. https://doi. org/10.1902/jop.1998.69.9.1027 Epub 1998/10/17. PubMed PMID: 9776031.

31. Lusvardi G, Malavasi G, Menabue L, Aina V, Morterra C. Fluoride-containing bioactive glasses: surface reactivity in simulated body fluids solutions. Acta Biomater. 2009;5(9):3548-62. https://doi.org/10.1016/j.actbio.2009.06.009 Epub 2009/06/16. PubMed PMID: 19523544.

32. Wilson J, Clark AE, Hall M, Hench LL. Tissue response to bioglass endosseous ridge maintenance implants. J Oral Implantol. 1993;19(4):295-302 Epub 1993/01/01. PubMed PMID: 8007022.

33. Bass CC. An effective method of personal oral hygiene; part II. J La State Med Soc. 1954;106(3):100-12 Epub 1954/03/01. PubMed PMID: 13143356.

34. Naumova EA, Sandulescu T, Bochnig C, Al Khatib P, Lee WK, Zimmer S, et al. Dynamic changes in saliva after acute mental stress. Sci Rep. 2014;4:4884. https://doi.org/10.1038/srep04884 Epub 2014/05/09. PubMed PMID: 24811301.

35. de Almeida Pdel V, Gregio AM, Machado MA, de Lima AA, Azevedo LR. Saliva composition and functions: a comprehensive review. J Contemp Dent Pract. 2008:9(3):72-80 Epub 2008/03/13. PubMed PMID: 18335122

36. Pessan JP, Conceicao JM, Grizzo LT, Szekely M, Fazakas Z, Buzalaf MA. Intraoral fluoride levels after use of conventional and high-fluoride dentifrices. Clin Oral Investig. 2015;19(4):955-8. https://doi.org/10.1007/ s00784-015-1426-3 Epub 2015/02/14. PubMed PMID: 25677244

37. Sanz M, Serrano J, Iniesta M, Santa Cruz I, Herrera D. Antiplaque and antigingivitis toothpastes. Monogr Oral Sci. 2013;23:27-44. https://doi.org/ 10.1159/000350465 Epub 2013/07/03. PubMed PMID: 23817058.

38. Choi HW, Um SH, Rhee SH. Preparation of fluoride-loaded microcapsules for anticariogenic bacterial growth using a coaxial ultrasonic atomizer. J Biomed Mater Res B Appl Biomater. 2018;106(1):31-9. https://doi.org/10. 1002/jbm.b.33810 Epub 2017/12/09. PubMed PMID: 29218856. 
39. Collins KD. Why continuum electrostatics theories cannot explain biological structure, polyelectrolytes or ionic strength effects in ion-protein interactions. Biophys Chem. 2012;167:43-59. https://doi.org/10.1016/j.bpc. 2012.04.002 Epub 2012/05/23. PubMed PMID: 22608112.

40. Naumova EA, Arnold WH, Gaengler P. Fluoride bioavailability in saliva using DENTTABS ${ }^{\circledR}$ compared to dentifrice. Cent Eur J Med. 2010;5:375-80.

41. Petersson LG, Arvidsson I, Lynch E, Engstrom K, Twetman S. Fluoride concentrations in saliva and dental plaque in young children after intake of fluoridated milk. Caries Res. 2002;36(1):40-3 Epub 2002/04/19. PubMed PMID: 11961329.

42. Sjogren K, Birkhed D, Persson LG, Noren JG. Salivary fluoride clearance after a single intake of fluoride tablets and chewing gums in children, adults, and dry mouth patients. Scand J Dent Res. 1993;101(5):274-8 Epub 1993/10/01. PubMed PMID: 8248728.

43. Aasenden R, Brudevold F, Richardson B. Clearance of fluoride from the mouth after topical treatment or the use of a fluoride mouthrinse. Arch Oral Biol. 1968;13(6):625-36 Epub 1968/06/01. PubMed PMID: 5244287.

44. Duckworth RM, Jones Y, Nicholson J, Jacobson AP, Chestnutt IG. Studies on plaque fluoride after use of F-containing dentifrices. Adv Dent Res. 1994; 8(2):202-7 Epub 1994/07/01. PubMed PMID: 7865076.

45. Duckworth RM, Maguire A, Omid N, Steen IN, McCracken Gl, Zohoori FV. Effect of rinsing with mouthwashes after brushing with a fluoridated toothpaste on salivary fluoride concentration. Caries Res. 2009:43(5):391-6. https://doi.org/10.1159/000239753 Epub 2009/09/25. PubMed PMID: 19776570.

46. Duckworth RM, Morgan SN, Murray AM. Fluoride in saliva and plaque following use of fluoride-containing mouthwashes. J Dent Res. 1987;66(12): 1730-4 Epub 1987/12/01. PubMed PMID: 3479472.

47. Song F, Koo H, Ren D. Effects of Material Properties on Bacterial Adhesion and Biofilm Formation. J Dent Res. 2015. https://doi.org/10.1177/ 0022034515587690 Epub 2015/05/24. PubMed PMID: 26001706.

48. Kerr WJ, Kelly J, Geddes DA. The areas of various surfaces in the human mouth from nine years to adulthood. J Dent Res. 1991;70(12):1528-30 Epub 1991/12/01. PubMed PMID: 1774384.

\section{Publisher's Note}

Springer Nature remains neutral with regard to jurisdictional claims in published maps and institutional affiliations.

Ready to submit your research? Choose BMC and benefit from:

- fast, convenient online submission

- thorough peer review by experienced researchers in your field

- rapid publication on acceptance

- support for research data, including large and complex data types

- gold Open Access which fosters wider collaboration and increased citations

- maximum visibility for your research: over $100 \mathrm{M}$ website views per year

At $\mathrm{BMC}$, research is always in progress.

Learn more biomedcentral.com/submissions 